\title{
Pyriform Sinus Fistula
}

\author{
Mariko Fujimatsu \\ Department of Pediatrics, Nippon Medical School Second Hospital
}
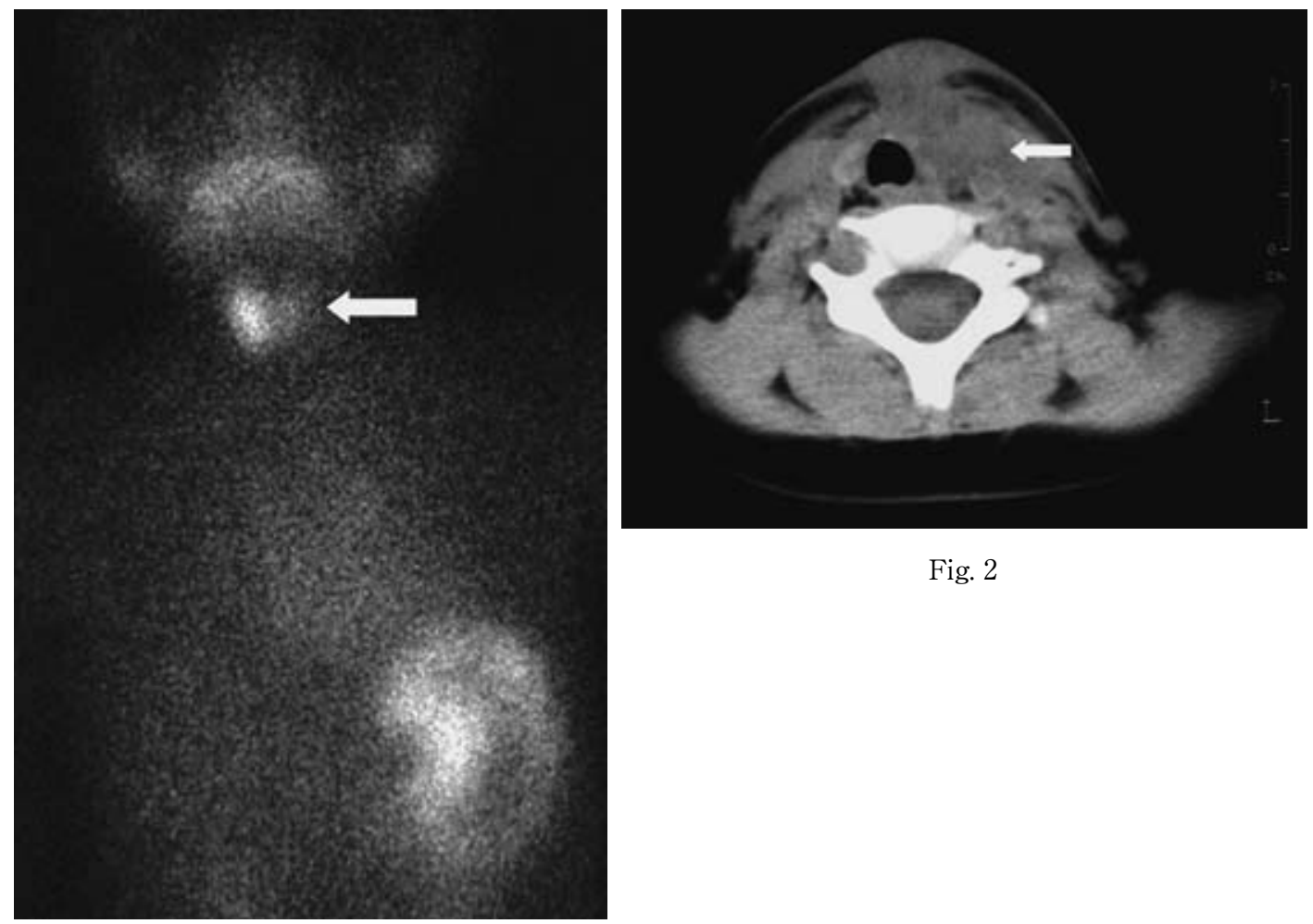

Fig. 2

Fig. 1

A 2-year-old boy with recurrent abscesses of on the left side of the neck due to pyriform sinus fistula is presented. Pyriform sinus fistula may cause acute suppurative thyroiditis and induce anterior cervical swelling, as in this case. Cervical computed tomography and barium swallow X-ray examination are important methods to diagnose of pyriform sinus fistula.

Nearly all reported pyriform sinus fistulae are on the left side. During normal embryologic development of the branchial apparatus, the fourth arch artery on the left side becomes part of the aortic arch, and the fourth arch artery on the right side becomes the proximal portion of the right subclavian artery. This asymmetric development of the branchial apparatus may explain the left-sided predominance of pyriform sinus fistula ${ }^{1}$. Furthermore, immunohistochemical studies have show that the fistulae are remnants of the ultimobranchial body, and trace the migration route of the ultimobranchial body to the thyroid gland ${ }^{2}$.

Complete removal of the sinus tract (fistula) should be considered to prevent recurrence. Treatment without fistulectomy, such as the use of antibiotics and drainage of the abscess, may allow recurrence.

Fig. 1 Technetium thyroid scan shows lowuptake in the left lobe with a shift of the thyroid gland to the right.

Fig. 2 Cervical computed tomography shows the thyroid gland with a markedly widely swollen left lobe.

Fig. 3 Barium swallow X-ray film demonstrates a shunt from the pyriform sinus to the thyroid gland (left). After operation this shunt is not observed (right).

Fig. 4 Illustration of the pyriform sinus fistula. A sinus tract is present between the pyriform sinus and a cystic structure of the left upper lobe of the thyroid gland (quoted from references ${ }^{3}$ ).

Correspondence to Mariko Fujimatsu, MD, Department of Pediatrics, Nippon Medical School Second Hospital, 1-396 Kosugi-cho, Nakahara-ku, Kawasaki, 211-8533, Japan

E-mail: azusa2go@nms.ac.jp

Journal Website (http://www.nms.ac.jp/jnms/) 

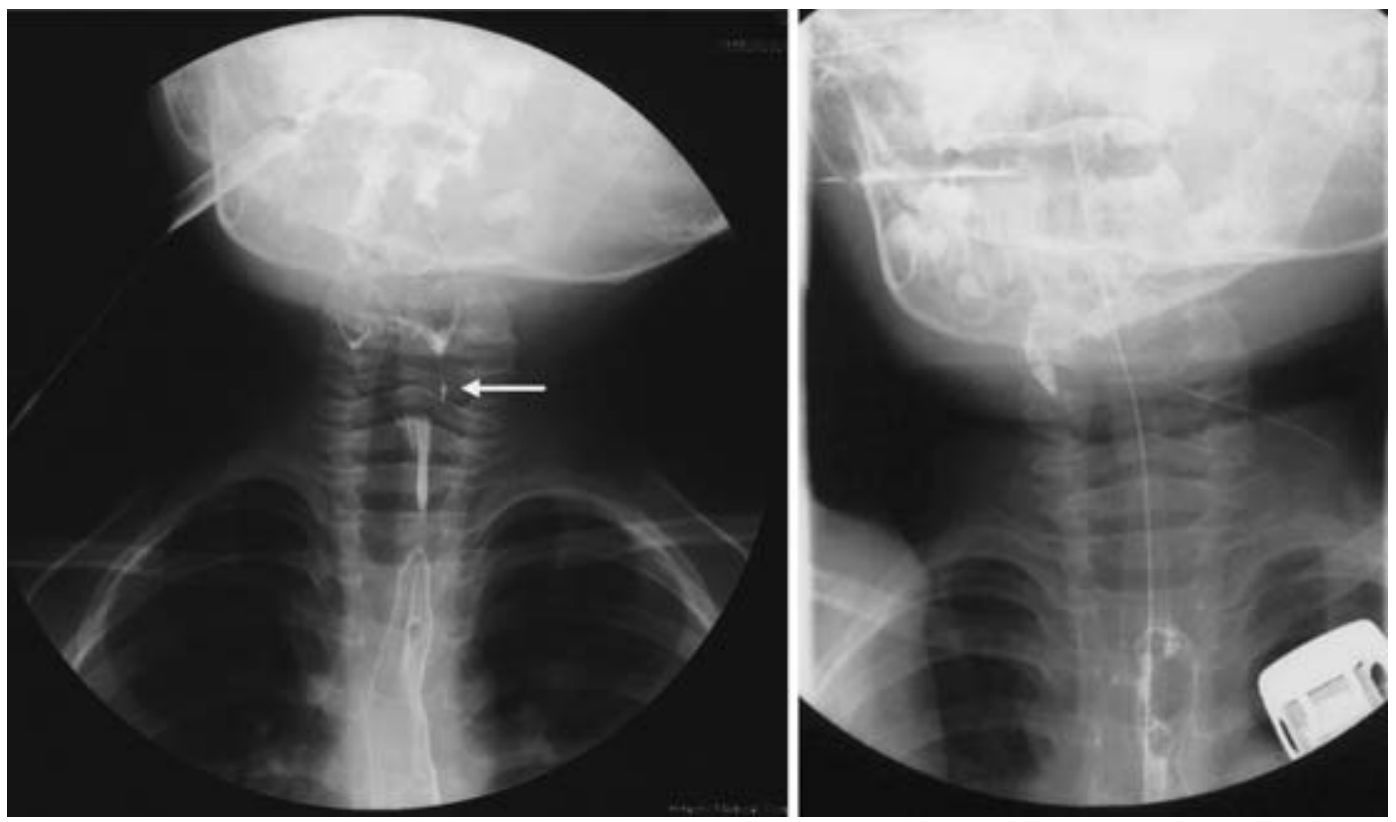

Fig. 3

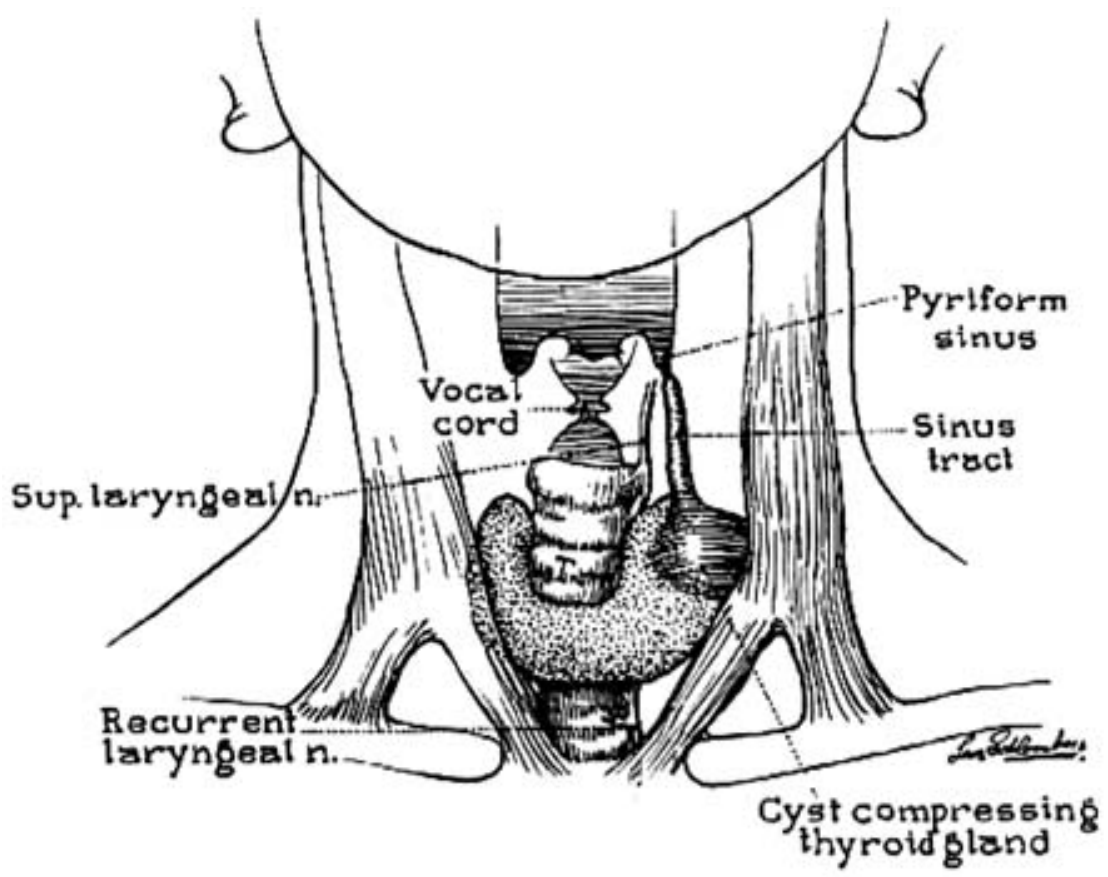

Fig. 4

\section{References}

1. Wang HK, Tiu CM, Chou YH, Chang CY: Imaging studies of pyriform sinus fistula. Pediatr Radiol 2003; 33: $328-333$.

2. Miyauchi A, Matsuzuka F, Kuma K, Katayama S: Piriform sinus fistula and the ultimobranchial body. Hiatopathology 1992; 20: 221-227.

3. Miller D, Hill JL, Sun CC, O’Brien DS, Haller JA Jr: The diagnosis adn management of pyriform sinus fistulae in infants and young children. J Pediatr Surg 1983; 18: 377-381. 